\title{
SUSTAINABILITY AND WASTE MANAGEMENT OF THE 2015 PRINCE GEORGE CANADA WINTER GAMES
}

\author{
JESSY RAJAN $^{1} \&$ ANNIE BOOTH ${ }^{2}$ \\ ${ }^{1}$ University of Northern British Columbia \\ ${ }^{2}$ Ecosystem Science and Management Program, UNBC
}

\begin{abstract}
Urban boosterism is increasingly being employed by cities around the world to garner provincial, national or even international attention. In an effort to rebrand and market itself as a 'Winter City', Prince George, Canada hosted the 2015 Canada Winter Games. However, urban boosterism focuses on economic influx and financial sustainability with little attention to environmental sustainability. Hosting mega-events like these results in a significant influx of visitors over a short period of time. To accommodate for this extreme change in a city's population, it is important to consider the concomitant environmental burden, particularly in terms of waste over the period of time and the need to dispose of it safely and properly. To examine the environmental impact of hosting this event, a waste audit was conducted on four of the venues to determine how much and what types of waste was accumulated. The largest contributor to the waste stream was food waste, occupying more than $1 / 3$ of the entire samples that was accumulated in the volunteer lounges. This study focuses on the consideration of waste types and areas in mega-events.
\end{abstract}

Keywords: mega-events, urban boosterism, waste audit, waste management.

\section{INTRODUCTION}

Whether it is a local music festival or a large-scale mega-event, cities are shifting toward hosting events that will booster their image. Events like these have potential to draw national and even international attention. This 'festivalization of urban politics' as described by Haubermann and Siebel, comes with the hope that events will spur economic development and rejuvenate aging infrastructure [1,2]. However, urban boosterism focuses on economic influx and financial sustainability, which provides a false or miscalculated anticipated economic influx, with little attention to environmental sustainability [3]. Hosting mega-events like these results in a significant influx of visitors over a short period of time [2]. To accommodate for this extreme change in a city's population, it is important to consider the concomitant environmental burden, particularly in terms of waste over the period of time and the need to dispose of it safely and properly.

Quite often, urban booster events will be related to sporting events. Varying from a global to continental to national scale, mega-events such as the Olympic Games, European Games and Canada Games are large-scale sporting events that are taken on by single cities. These sporting events have similar structures and organization with a council or committee that acts as a governing body [4-6]. Cities will bid to host the event and the International Olympic Committee, European Olympic Committee and Canada Games Council, respectively, make the final decision on which city is awarded the event. Sochi, Russia, Baku, Azerbaijan and Prince George, Canada have commonalities as host cities in their desire to be highlighted on

This paper is part of the Proceedings of the $7^{\text {th }}$ International Conference on Sustainable Tourism (Sustainable Tourism 2016)

www.witconferences.com 
a larger scale: for Sochi to be recognized globally, Baku to have a stronger presence in Europe and Prince George to gain national recognition [4-6].

In these three cities, the desire to be highlighted and showcased to a wider audiencwe is the desire for growth. There is a temporary sudden influx of tourism during the sporting event and is an opportunity to brand the city in a new way [7]. In the 2015 Games, Prince George took on the branding as a 'Winter City' with the slogan 'we are winter' [8, 9]. The hope was that visitors would be enticed by winter recreation activities and either return for visits or move here. For the Olympics, it was an opportunity for boosterism for Sochi, but also for Russia to rebrand and position itself as a strong country [7]. Similarly, in Baku's bid for the European Games, President Illham Aliyev claimed 'the rejuvenating and modernizing Baku has already secured a rightful place in the world map' [10]. In their own ways, these cities needed the Games to portray a certain image. Cities will continue to host such events to compete for industry, investment and tourism, but it is important that the environmental impact be considered in doing so as it impacts the quality of life [1].

Large-scale sporting events are becoming increasingly aware of the environmental impact and issues of waste accumulation resulting from hosting these events. This awareness has led to waste monitoring and measuring as a sustainability initiative in many events. With efforts to monitor waste accumulation, initiatives to reduce and divert waste have developed and have been used in a number of Canadian sporting events including the Vancouver Olympics, previous Canada Games and the recent Alberta Winter Games [11, 12]. There is some research and information on waste diverted in other large-scale sporting events already, but areas that are missing include the types of waste that is generated in sporting events. Knowing the content of waste is a critical component of planning for waste management. This research looked at the overall waste impact of hosting the 2015 Canada Winter Games in Prince George, British Columbia, Canada.

In February 2015, Prince George was the host to the Canada Winter Games, an 18 day event that attracted approximately 8,000 people to the city from every province and territory in Canada [13]. In the span of 18 days, 21 venues across the Prince George area hosted 19 official sports that were accompanied by nightly festivities and fireworks [13]. The Canada Games are unique sporting events; it is the largest sporting competition in the world of national level competition for junior athletes [14]. While events celebrating young athletes and encouraging the growth of sport and recreation across the country are commendable, the events must be manageable for the host cities.

Previous Canada Games have been held in similar-sized cities in various provinces and territories across the country, but Prince George is an urban centre uniquely located in a northern, rural setting with limited waste diversion facilities. Waste management practices in the 2011 Halifax Winter Games and the 2013 Sherbrooke Canada Summer Games had access to previously implemented waste diversion plans for both the venues and host cities $[15,16]$. At these Games, the Host Societies had committed to tracking waste and were able to provide total tonnes of waste diverted $[15,16]$.

This research sought to look at:

- How much waste was diverted?

- How much could have been diverted into the main waste streams (based on reports indicating the highest volumes of waste): paper products, plastic, refundable/consumable beverage containers, mixed materials, food and other?

- What types of waste are generated in sport related events? 


\section{METHODS}

Waste audits had been conducted at a regional level on two prior occasions at the local landfill that serves Prince George that had indicated the need for a new waste management plan $[17,18]$. Similar to the audits conducted at the Foothills Landfill, a waste audit was carried out at the University of Northern British Columbia [19]. These audits influenced this study's protocol and methods. The greatest components of waste are generally food, paper and plastic [17-19].

The waste audit and characterization study was carried out through the duration of the 18 day event. There were four identified sample sites that were representative of the 19 venues at which the Games-related events were held. Samples were collected on 12 of the 18 days on a staggered schedule. There were 48 samples in total.

The 2015 Canada Winter Games were held over several venues in the Prince George area that ranged from multipurpose recreation facilities to high school buildings to an open plaza; including a variety of indoor and outdoor venues. To be representative of the different types of hosting spaces, the following sample sites were selected with the variety of uses in mind: Civic Centre, CN Centre, Northern Sport Centre and Otway Nordic Ski Centre.

Both Civic Centre and CN Centre are City owned and operated. Civic Centre is a venue located in central downtown that is commonly used for conventions, trade shows, meetings and other events in the 40,000 square foot building. It was used as a feeding centre for athletes with a small medical clinic on the second floor; medical waste was disposed separately and not included in the audit. CN Centre held hockey games and the opening ceremonies; the multi-purpose arena seats over 5,000. The Northern Sports Centre held five official sports and is a City owned building that is operated by the UNBC; it is a multi-purpose venue with facilities ranging from indoor track to general fitness. Otway Nordic Ski Centre is a network of trails primarily for cross country skiing that is operated by a volunteer board of directors and is part of non-profit organization; this was the only outdoor venue sampled.

At these four sample sites, a bag of garbage was collected on each sampling day. The bags of garbage were sometimes left by the volunteers for collection, or were sometimes taken from the dumpster and on occasion, when dumpsters were empty or locked, samples were taken from bins. On sampling days, samples were collected from all four sites within an hour of each other. Time of day for sampling was on a staggered schedule that allowed for a variety of collection times.

Upon collection, most of the samples were characterized and processed the same day. The samples that were taken at night were processed the following morning. All samples were weighed at time of collection and before characterizing to determine or account for any changes in weight.

Characterization and processing samples involved emptying the bags of garbage entirely and assessing the contents. The contents were classified into material categories: recyclable plastic, non-recyclable plastic, recyclable paper, non-recyclable paper, refundable bottle and can recycling, mixed materials and food waste. Table 1 outlines the contents of these categories.

The samples were sorted into the categories listed in Table 1 and weighed to determine ratio of each category present in the bag. This characterization only made assessments based on their weight and did not consider volume. The assessment within each category included counts for numbers of paper cups, numbers of Styrofoam bowls, etc.

There was a component of the study that was meant to be conducted by the Host Society volunteers which was to collect and weigh all waste prior to disposal. This meant weighing 
all the bins of garbage as well as the two different streams of recycling. This aspect of the study was conducted by the organization's volunteers and not by the researcher.

\section{RESULTS}

There were two components to this study to look at the waste generation and to assess the waste composition. The data collected from the Host Society were incomplete and not an accurate depiction of the waste that was generated throughout the 18 day event. There were multiple absences of data in the findings. In turn, this study emphasizes the types of waste that are generated in sport related events.

One of the greatest contributors to waste in hosting the 2015 Prince George Canada Winter Games was food. The food appeared to be generated in the volunteer lounges for the sample sites: CN Centre, Northern Sports Centre and Otway. Civic Centre primarily produced food waste or waste associated with food preparation as it was an athlete feeding venue. The results of the waste study identified the need for food waste diversion.

Table 2 outlines the actual cumulative measurements, in grams of waste collected in each waste category for the corresponding sample site. These were the total weights that were taken from 48 samples. Figure 1 shows the percentage breakdown of each category.

Occupying over $1 / 2$ of the samples, food was the greatest contributor to the waste stream. In 48 samples (48 bags of garbage), $13.38 \mathrm{~kg}$ of food was found. This could possibly mean that food waste holds a greater wet mass than other types of waste or it could be indicative of the larger ratio of food waste generation. Some assumptions about the food waste category could be made on consumer behaviour and food preparation in events.

Some sources of food waste identified some consumer behaviour habits. It was clear that many of the samples of waste were generated in the volunteer lounge areas of the sample sites. These lounge areas provided a variety of food to volunteers that was easy to serve. Some of the food waste consisted of items of food that had only partially been eaten (i.e. an apple with only one bite).

Easy to serve food is generally associated with disposable packaging or cutlery. A large portion of the recyclable plastics included Styrofoam bowls and cups that were used to serve

Table 1: Waste characterization categories.

\begin{tabular}{ll}
\hline Recyclable plastic & $\begin{array}{l}\text { Accepted within recycling facilities in the Regional } \\
\text { District Fraser Fort George (RDFFG) }\end{array}$ \\
Non-recyclable plastic & Plastic with adhesive: tape, stickers \\
Recyclable paper & Accepted within recycling facilities in RDFFG \\
Non-recyclable paper & Food contamination, used napkins/paper towels \\
Refundables & Refundable beverage containers: plastic bottles, cans, Tetra Pak \\
Mixed materials & Aseptic/Gable top/Tetra \\
& Steel, tin cans \\
& Wood \\
& Aluminum \\
Food waste & Food items \\
Other & All other content \\
& Unrecognizable waste \\
\hline
\end{tabular}




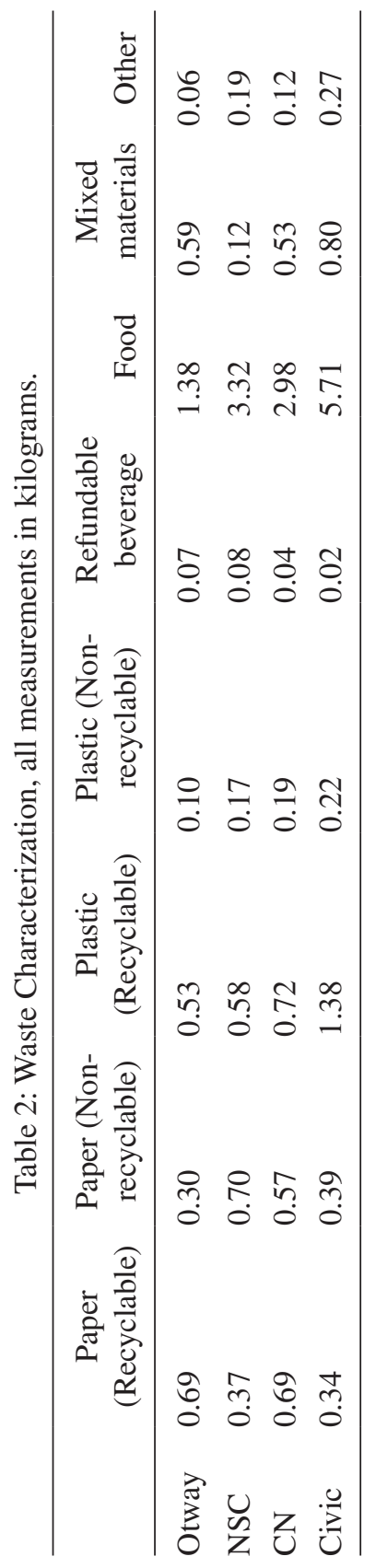


hot meals or for coffee. The Games were not providing any single use water bottles to athletes or volunteers and instead, provided water refill stations. This generated a large number of plastic cups in the samples. The non-recyclable plastic was generally associated with food wrapping; plastic film for sandwiches and other food items.

The paper category of the characterization included a range of products, depending on the location of the waste bin. The waste samples that appeared to be from the washrooms included a great deal of paper towel; only two of the overall samples appeared to have originated in a washroom. The rest of the samples generated many paper coffee cups in the paper product category. Some volunteer lounge waste also generated paper soup bowls. Paper products that were not considered recyclable were cups that were far too contaminated by food waste or for sanitary reasons.

Mixed materials was a widely ranging category and thus generated an equal variety of contents in the samples. This category ranged based on location more than any of the categories as it included miscellaneous items that ranged from batteries to aluminium foil to tin cans. The item that was dominant in this category by volume, although contributing little weight, was polypropylene; aluminium foil-lined plastic generally from granola bars. The samples showed that granola bars were likely distributed in volunteer lounges, athlete resting areas and in other general spaces as they did not seem tied to a specific location.

Based on the final report from the 2015 Canada Winter Games, the total diversion of waste from the landfill was $24 \%$. Targets were initially set at $80 \%$ and brought down to $65 \%$ when an option for food waste diversion could not be secured. The $24 \%$ that was diverted included refundable beverage container recycling, hard plastic and tin container recycling and paper products as these were the services as provided by Emterra: the recycling collection company that was contracted by the Games. Recycling that was made available at the venues did not encompass all materials that can be recycled within the RDFFG.

Food waste is one of the more egregious forms of human waste due to the embedded environmental, economic and social costs associated with its production, distribution, and disposal. In a culture formed in an expansive landscape rich in resources and environmental

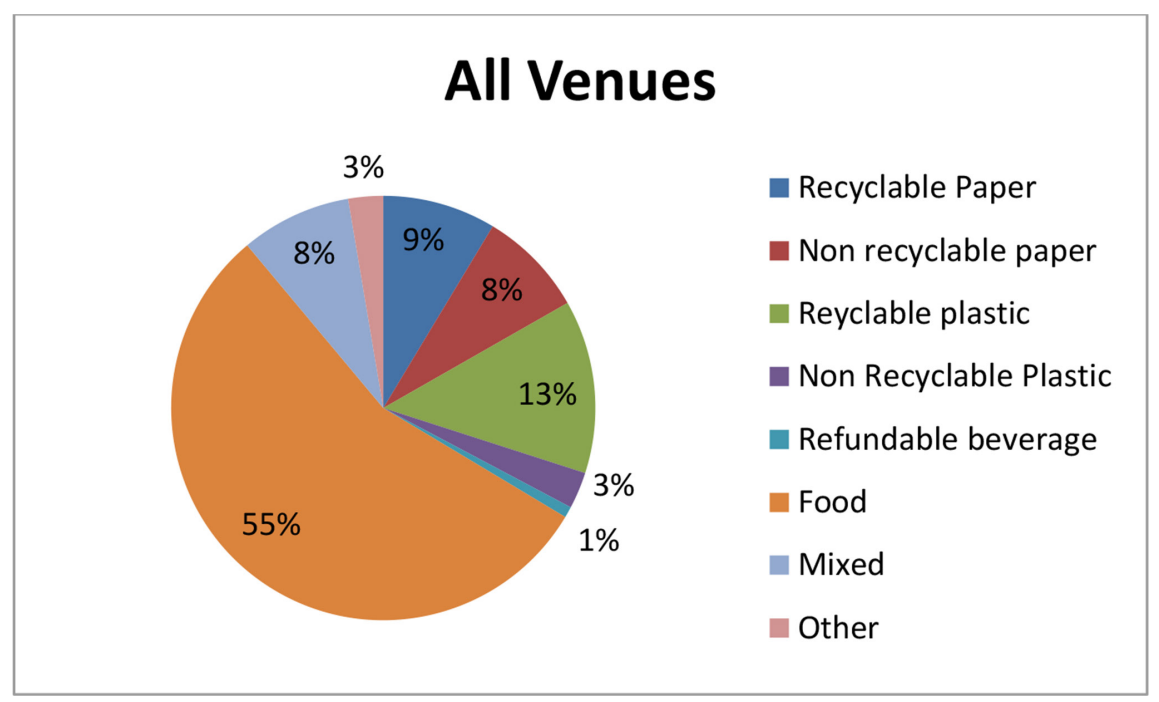

Figure 1: Waste characterization. 
amenities, there is not a significant regard to environmental protection and is, therefore, lacking in waste minimization or handling facilities. Another challenge facing rural and northern communities of $\mathrm{BC}$ is the low reliance on local food systems. With food occupying the greatest ratio of waste in samples, it is clear that a diversion stream for waste was needed. There were some contextual issues discussed that suggest organizers of these events need to understand the local context to meet the waste management needs of the event.

\section{CONCLUSIONS}

In identifying the impact, large-scale events will have on host cities, there needs to be a focus on environmental impacts rather than just economic impacts. There is a heavy focus on the economic benefit in attracting and hosting events with minimal consideration as to their environmental burden. The environmental or sustainability efforts tend to be implemented far too late in the planning process. To host low-impact events, there needs to be an environmental impact assessment including estimating the likely influx of waste associated with the event.

When planning multi-day events, it is important to consider the type of waste that will be generated and accounting for appropriate waste management. This, in part, is a relationship between the purchasing department and waste management planning. This study has shown that the majority of waste accumulated at the 2015 Games, was related to food; it was either food products or the associated packaging/serving materials. It is critical to understand the type of waste the event will generate to effectively prepare for waste management procedures. Efforts to minimize waste accumulation or toward waste diversion will be more successful when there is a stronger sense of its content.

The 2015 Games would have been more successful in meeting their waste diversion goals if there was a stronger understanding of the type of waste that would be generated. While each venue was equipped with three stream bins, they were not suitable for the venues. The streams provided were suitable for household/residential waste while this study found that events need strategies in place for excess food waste.

In the future, waste audits could be enhanced by using different metrics of comparison. For example, using weight to define content ratios between waste categories ruled out the consideration of volume or toxicity. Food waste occupied more than $1 / 3$ of the weight of all samples, but there is little indication of its volume in the overall samples. The refundable beverage container category was captured by a small percentage in weight, but could have had a stronger contribution if measured in volume. It would be useful to explore other practices or procedures that could account for these variables and provide a more accurate study. Toxicity also plays an important role in assessing the environmental impact of waste generation; some types of waste will be more toxic while decomposing.

\section{REFERENCES}

[1] Roth, S. \& Frank, S., Festivalization and the media: Weimar, cultural capital of Europe 1999. International Journal of Cultural Policy, 6, pp. 219-241, 2000. http://dx.doi.org/10.1080/10286630009358122

[2] Hiller, H.H., Mega-events, urban boosterism and growth strategies: An analysis of the objectives and legitimations of the cape town 2004 Olympic Bid. International Journal of Urban \& Regional Research, 24, pp. 439-458. 2000.

http://dx.doi.org/10.1111/1468-2427.00256

[3] Matheson, V., Mega-events: the effect of the world's biggest sporting events on local, regional, and national economies. Economics Department Working Papers, Paper 68, pp. 1-32. 2006. 
[4] International Olympic Committee, The Organization, available at www.olympic.org/ about-ioc-inistitution, 2015.

[5] European Olympics Committee, ENOCS, available at www.eurolympic.org/en/enocs-2. html, 2016.

[6] Canada Games Council, About Us, available at www.canadagames.ca/content/aboutus/home.asp/, 2015.

[7] Ostapenko, N., Nation branding of Russia through the Sochi Olympic Games of 2014. Journal of Management Policy and Practice, 11(4), pp. 60-63. 2010.

[8] Canada Winter Games, The Northern Story, available at www.canadagames2015.ca, 2014.

[9] Kurjata, A., Canada winter games in Prince George: 5 things to know, $C B C$, British Columbia, 2015.

[10] Koch, N. \& Valiyev, A., The Sochi syndrome Afoot in Central Asia. PONARS Eurasia Policy Memo No, 371, 2015.

[11] AWG, A.W., 2014 Alberta winter games environmental sustainable advisory committee final report, Banff- Canmore, Alberta Winter Games, 2014.

[12] VANOC, Vancouver 2010 sustainability report 2009-2010, Vancouver, VANOC, 2010.

[13] Host Society, Canada Games Legacy, 2014, available at www.canadagames2015.ca/ about-the-games/canada-games-legacies[14] Canada Games Council, Introduction, available at www.canadagames.ca/content/Games/Home.asp,2014.[15] $\quad \mathrm{H}$ a $\mathrm{l}$ i f a x Host Society, Halifax: 2011 Canada winter games environmental services final report, 2011.

[14] Host Society., Sherbrooke: Canada summer games, sustainable report Sherbrooke, 2013.

[15] TRI, T.R., Waste characterization study foothills Boulevard Landfill. Prince George: Regional District Fraser-Fort George, 2007.

[16] RDFFG, R.D.-F., A feasibility study on enhancing waste diversion from the residential curbside solid waste stream in the city of Prince George. Prince George: Regional District of Fraser-Fort George, 2011.

[17] Smyth, D.P., Fredeen, A.L. \& Booth, A.L., Reducing solid waste in higer educations: the first steps toward 'greening' a campus. Resources Conservation and Recycling, 54, pp. 1007-1016, 2010.

http://dx.doi.org/10.1016/j.resconrec.2010.02.008 